\title{
Caso clínico-radiológico adulto
}

\author{
EDUARDO SABBAGH P.*, KAREN CZISCHKE L.*,**, GABRIELA TERÁN P.**, \\ CRISTIÁN CUADRA C.** y CRISTINA FERNÁNDEZ F.****
}

Mujer de 49 años diabética tipo 2, no fumadora. Hace un año se muda a una casa donde habitan y anidan palomas. Consulta por historia de dos meses de disnea progresiva hasta el reposo. Se agrega tos seca y baja de peso de $7 \mathrm{~kg}$. Sin fiebre, dolor torácico, ni hemoptisis.

$\mathrm{Al}$ examen físico destaca frecuencia respiratoria aumentada 32 por min, taquicardia, presión arterial normal, oximetría de pulso $92 \%$ respirando aire ambiental. No hay hipocratismo. Crepitaciones difusas en ambos campos pulmonares, sin sibilancias.

Fue incapaz de realizar exámenes de función pulmonar. Distancia recorrida en test de caminata de 6 min corresponde al $85 \%$ de su valor teórico normal, con oximetría inicial y final 94 y $76 \%$ respectivamente, lavado broncoalveolar: $44 \times 10^{6}$ células $/ \mathrm{ml}$, linfocitos $52 \%$. IgG deposiciones de paloma $>200$ UI, IgG especifico suero de paloma positivo 0,603 UI.

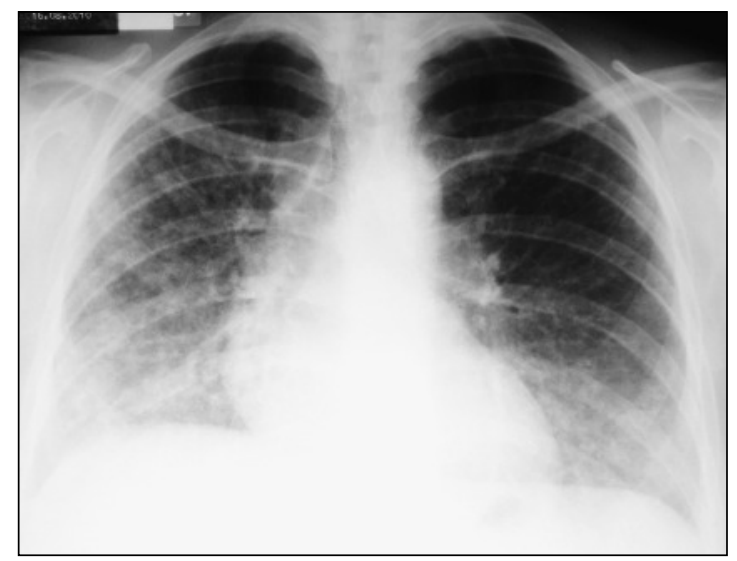

Figura 1. Rx tórax (16 de agosto).
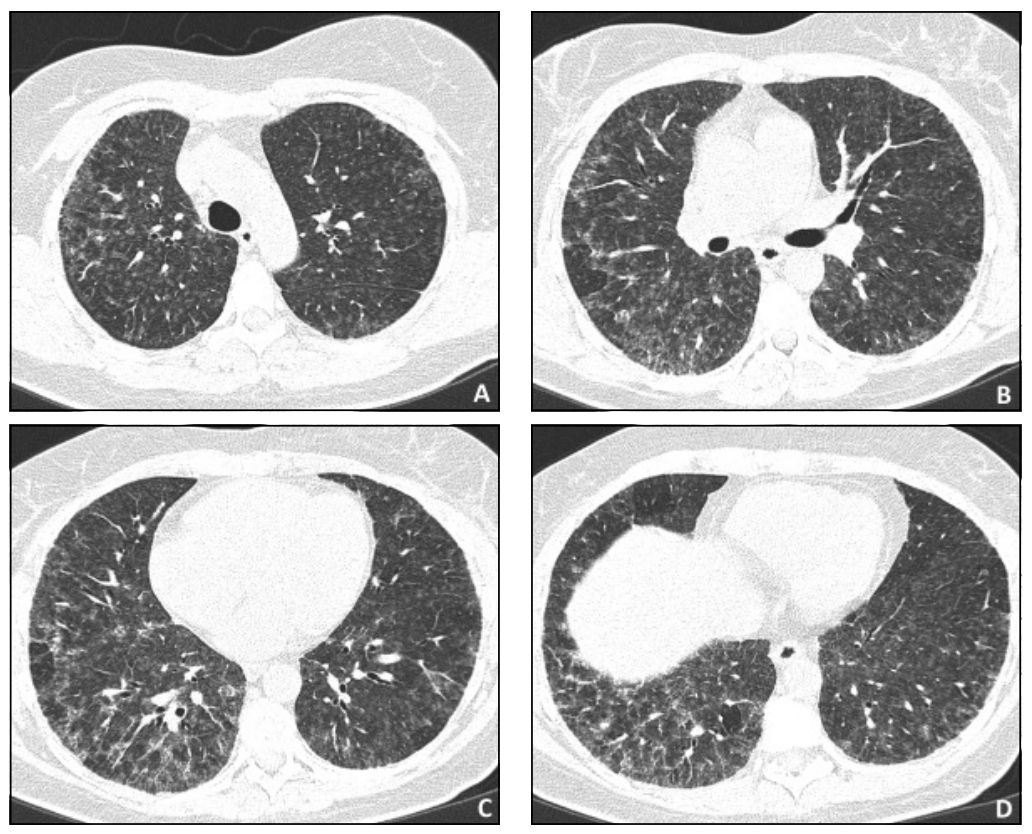

Figura 2. Cortes de Tomografía Computarizada de tórax (19 de agosto).

Describa el patrón radiológico, considerando distribución, tipo lesional, y proponga posibles diagnósticos.

\footnotetext{
* Instituto Nacional del Tórax.

** Universidad de Chile.

***Universidad de Los Andes.
} 


\section{Descripción}

La radiografía póstero-anterior del 16 de agosto (Figura 1), demuestra una enfermedad pulmonar difusa, de predominio basal, más severa en el lado derecho, con distribución segmentaria, caracterizada por aumento de la densidad radiológica, con arquitectura conservada.

Los cortes de tomografía computada de tórax (TC) del 19 de Agosto (Figura 2 A, B, C y D), además de lo observado en la radiografia, demuestran que el proceso genera predominantemente una imagen de "vidrio esmerilado" e incluso en algunas áreas hay condensación leve. Este proceso en áreas menos comprometidas tiene un aspecto "moteado", algo granular, mal definido, que corresponde a compromiso de regiones centro acinares. También la TC muestra focos de atrapamiento de aire que comprometen a subsegmentos y lobulillos y algunos tabiques perilobulillares engrosados, regulares. Es importante recalcar la conservación de la arquitectura pulmonar, sin elementos sugerentes de fibrosis.

\section{Discusión radiológica}

Radiológicamente es una enfermedad pulmonar difusa ${ }^{1}$. En ella predomina claramente un aspecto activo (vidrio esmerilado y condensación) sin elementos de fibrosis como arquitectura desorganizada, finas opacidades irregulares, microquistes o panal.

Además la distribución segmentaria, hace considerar la posibilidad de neumonitis por hipersensibilidad y broquiolitis obliterante con neumonía organizada (BOOP) o neumonía organizante criptogénica (COP). Otros procesos que pueden simular este patrón son sarcoidosis alveolar, procesos linfoproliferativos y neoplasia bronquiolo-alveolar. La sarcoidosis es de predominio en los tercios medios y se acompaña de compromiso ganglionar hiliar simétrico y mediastínico medio. En los linfomas el compromiso ganglionar y de otros órganos es frecuente. $\mathrm{La}$ neoplasia bronquiolo-alveolar en fase neumónica con diseminación broncógena presenta un foco de condensación predominante y la diseminación es más nodular.

Nuestra paciente tiene dos aspectos llamativos que diferencian su patología de una COP. Uno es el "moteado" centro acinar, que traduce el compromiso inflamatorio del parénquima peribroncovascular, debido a que la causa está relacionada a la vía aérea (alergeno inhalado). Cuando esta imagen está presente es muy sugerente de neumo-

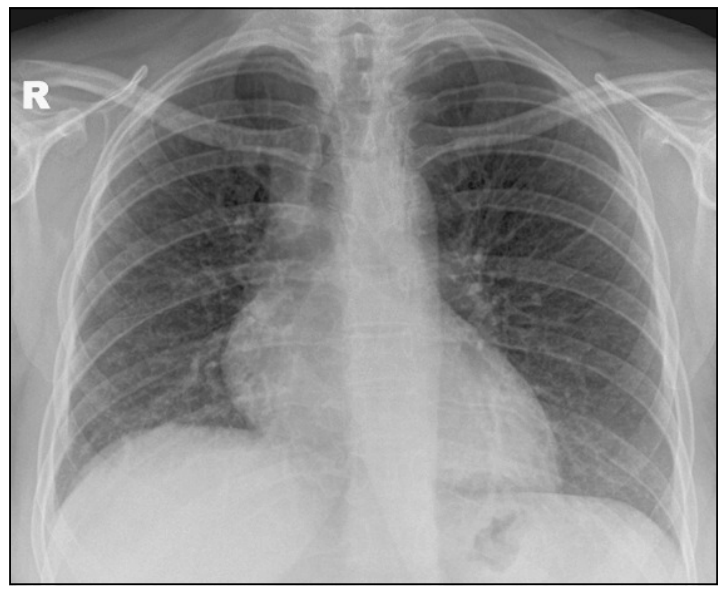

Figura 3. Rx tórax control post alta (14 de septiembre).

nitis por hipersensibilidad, en la etapa I (aguda) y especialmente en la etapa II (subaguda) ${ }^{2}$. El otro elemento llamativo es la presencia de focos de atrapamiento de aire, que traduce el compromiso inflamatorio de la vía aérea, con obstrucción parcial de ella.

Así del punto de vista de las imágenes el proceso patológico que afecta a nuestra paciente es sugerente de neumonitis por hipersensibilidad.

\section{Hallazgos anátomo-patológicos}

Biopsia transbronquial: Hallazgos morfológicos sugerentes de neumonitis por hipersensibilidad, con algunos focos de BOOP.

\section{Evolución}

Por la severidad funcional la paciente se trató con prednisona y se le aconsejó cambiar de domicilio. En su control después del alta hubo una clara mejoría clínica y radiológica (Figura 3).

\section{Diagnóstico final}

Los hallazgos clínicos, radiológicos, anatomopatológicos y la respuesta a tratamiento sugieren: neumonía por hipersensibilidad subaguda a palomas.

\section{Comentario}

La neumonía por hipersensibilidad (NHS) ${ }^{3} \mathrm{o}$ alveolitis alérgica extrínseca (AAE) es un síndrome complejo que varía en su agente etiológico, formas de presentación clínica y evolución. 
Representa una reacción inmunológica del parénquima pulmonar a un agente inhalado, (particularmente agentes orgánicos). En la literatura se han comunicado más de 300 posibles etiologías. ${ }^{4}$

La incidencia de AAE por palomas en EE.UU. varía entre $6.000-21.000$ por 100.000 habitantes por año con una prevalencia $6-21 \%$ por año. La NHS causada por aves, puede ser inducida por la exposición a las excretas y/o a material proteináceo ${ }^{5}$.

La clasificación clásica de aguda, subaguda y crónica se basa en el curso clínico y la intensidad de la exposición al agente causal. Las características patológicas se fundamentan en la presencia de granulomas no caseificantes mal definidos que pueden acompañarse de bronquiolitis con o sin neumonía organizativa y fibrosis intersticial. ${ }^{67}$ El antecedente de exposición es fundamental y los hallazgos en los exámenes que orientan al diagnóstico son, LBA con linfocitosis ${ }^{8}$ y distintos grados de hipoxemia. Las pruebas de función pulmonar muestran un patrón principalmente restrictivo, con disminución en la capacidad de difusión. El hallazgo de precipitinas IgG positivas contra antígenos conocidos como catas y palomas son de utilidad etiológica.

El tratamiento va a depender del tipo de NHS. Es fundamental retirar al paciente de la exposición al antígeno. El uso de glucocorticoides sistémicos como tratamiento estándar para la enfermedad severa está basado en experiencias del pulmón del granjero.

\section{Bibliografía}

1.- MULLER N, FRASER R, COLMAN N. Radiologic Diagnosis of diseases of the Chest, Chapter 9 Chronic interstitial lung disease. Philadelphia:WB Saunders Co.200167-155.

2.- HIRSCHAMANN J V, PIPAVATH S N, GODWIN J D. Radiographics 2009; 29: 1921-38.

3.- LACASSE Y, SELMAN M, COSTABEL U, DALPHIN J C, MASAKUYI A, MULLER N, et al. Clinical diagnosis of hypersensitivity pneumonitis Am J Respir Crit Care Med 2003; 168: 952-8.

4.- CORMIER Y, LACASSE Y. Keys to the diagnosis of hypersensitivity pneumonitis: The role of serum precipitins, lung biopsy, and high-resolution computed tomography. Clin Pulm Med 1996; 3:72.

5.- INASE N, OHTANI Y, SUMI Y, UMINO T, USUI Y. A clinical study of hypersensitivity pneumonitis presumably caused by feather duvets. Ann Allergy Asthma Immunol 2006; 96: 98-104.

6.- KATZENSTEIN A L, MUKHOPADHYAY S. Hum Pathol 2008; 39: 1275-94.

7.- TAKEMURA T, AKASHIT, OHTANI Y, INASE N, YOSHIZAWA Y. Pathology of hypersensitivity pneumonitis. Curr Opin Pulm Med 2008; 14: 440-54.

8.- OHSHIMO S, BONELLA F, CUI A, BEUME M, KOHNO N, GUZMAN J, COSTABEL U. Significance of bronchoalveolar lavage for the diagnosis of idiopathic pulmonary fibrosis. Am J Respir Crit Care Med 2009; 179: $1043-7$. 